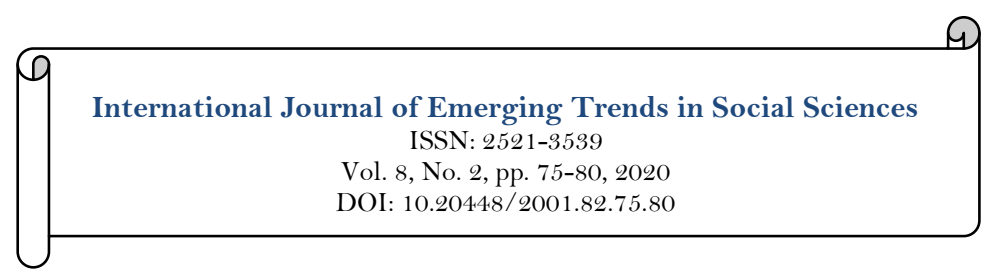

Strategies to Grow and Expand a Nonprofit Business

\author{
Olusegun Awode ${ }^{\text {* }}$ \\ Peter Anthony ${ }^{2}$ \\ ${ }_{1,2}$ Walden University, USA. \\ Email:segunawode@yahoo.com
}

\begin{tabular}{l|l}
\multicolumn{3}{|c}{ Abstract } & \\
Nonprofit organizations make significant contributions to individuals, & Keywords: \\
organizations, communities, the environment, and societies, but many do not & Business growth \\
survive in the long run. This study is important to business leaders in for- & Business expansion \\
profit and nonprofit organizations who want to implement strategies for the & Business growth \\
long-term survival of their business, improve business performance, and & Penrose theory of growth \\
effect positive social change. Grounded in Penrose's theory of growth, the & Penrose \\
purpose of this qualitative single-case study was to explore strategies leaders & Nonprofit business or \\
used to grow and expand a nonprofit business in the midwestern region of & organization. \\
the United States. The participants comprised 5 nonprofit leaders with & Licensed: \\
recorded success at growing and expanding their business. Data were & This work is licensed under a \\
collected from semistructured interviews and document reviews involving the & Creative Commons Attribution 4.0 \\
governance system, programs, strategies, operations, partners, and budget. & License. \\
Thematic analysis was used to analyze the data. Four themes emerged: & Publisher: \\
strategic planning cycle, effective fundraising planning and strategy, resource & Scientific Publishing Institute \\
and financial assessment, and team development and positive working & Received: 12 May 2020 \\
conditions. A key recommendation includes that nonprofit leaders seeking & Revised: 10 June 2020 \\
growth and expansion engage in effective strategic planning. The & Accepted: 14 July 2020 \\
implications for positive social change include the potential for leaders of & Published: 17 August 2020 \\
nonprofit organizations to provide growth and expansion strategies to & \\
increase their organizations capacity for positively transforming & \\
communities by maintaining or improving available opportunities and & \\
services. &
\end{tabular}

Funding: This study received no specific financial support.

Competing Interests: The authors declare that they have no competing interests.

\title{
1. Strategies to Grow and Expand a Nonprofit Business
}

Nonprofit organizations are civil society actors because of their roles in policy making, innovation, cost effectiveness, their ability to work with local communities, and the public benefits they offer (Appe, 2019). Stork and Woodilla (2008) noted that nonprofit organizations experienced explosive growth in total organizations, employment, revenues, organizational mix, and assets with registration that grew by $30 \%$ to 1,409,628 between 1996 and 2006. There are many challenges associated with the operations of nonprofit business. Kim, Charles, and PettiJohn (2019) identified two key challenges associated with the performance management of nonprofit organizations, which are lack of resources and lack of analytical capacity, while lack of support from the board of directors is considered as a low issue. Kim et al. highlighted that nonprofit leaders do not fully understand what to measure and how to generate insights from the results because performance management has become very complex. The use of performance management data is very important for the growth and expansion of nonprofit business. 
A significant percentage of small- and medium-sized enterprises go out of business within 5 years of establishment (Ifekwem \& Adedamola, 2016). Fifty percent of the nonprofit businesses in the United States cease operations in fewer than 5 years (U. S. Small Business Administration (SBA), 2018). The general business problem is that some leaders of small and medium-sized nonprofit enterprises lack effective strategies to help ensure sustainable growth and expansion. The specific business problem is that some leaders of nonprofit enterprises lack effective strategies to grow and expand their business. The data from this study might provide some supporting evidences that will indicate the immense benefits associated with the growth and expansion of a nonprofit business.

\section{A Review of the Professional and Academic Literature}

The literature review is a critical component of a research study that a researcher uses to support relevant topic with current knowledge that is associated with the topic (Marshall \& Rossman, 2016). I organized the literature review relevant to themes related to the conceptual framework of the theory of growth of firms which are the human motivation and economic principles' concepts of the theory, and information related to small businesses. I gathered scholarly literature from various sources, such as Google Scholar, ScienceDirect, ProQuest Central, Management \& Organization Studies, book, and governmental websites, that includes the SBA, and SAGE Premier.

I selected the theory of growth of firms as the conceptual framework for this study. Penrose (2009) covered in The Theory of the Growth of the Firm, in 1959, the productive opportunity of the firm, expansion through or without merger and acquisition, diversification, and the rate of growth of a firm. Kor, Mahoney, Siemsen, and Tan (2016) noted that the theory helped to develop the resources approach, and hence, considers the resource-based view of the firm in its approach. Penrose identified two modes of growth which are organic growth and acquisitive growth for expansion (Kor et al., 2016).

The theory of growth of firms is frequently cited in scholarly research and is worthy of academic research for the growth and expansion of a nonprofit business.

\section{Human Motivations}

Organizations are artificial beings that require human beings to run these firms on a daily basis. Grillitsch, Schubert, and Srholec (2019) in a study on processes that drive various forms of innovation to establish a relationship with firm growth involving small and medium-sized firms in Sweden, found that significant positive effects existed of the three knowledge types on firm growth and that even slow-growth firms benefited from the combination of knowledge bases. In another study to explore the influence of environmental challenges of business on the growth of informal business in Uganda, the researchers found that a significant and positive direct relationship between the internal environment and the growth of informal business, but a significant negative relationship between external environment and the growth of the firm (Struwig, Krüger, \& Nuwagaba, 2019). The internal environment of a firm is influenced by the human interactions therein. Castaño, Méndez, and Galindo (2016) highlighted that potential competition positively affects product innovation and indirectly affects internationalization of entrepreneurs in the service sector. Companies that have competent personnel and new technologies have more innovations and internationalize within their first year of operation, which in turn, positively affects business growth expectations.

There are additional growth factors that are associated with businesses. Powe (2018) highlighted that small- and medium-sized enterprises (SMEs) can be leading firms within low-income settlements and helped to stabilize but not revive their fortunes, while non-amenity factors like landscape; culture and heritage helped with the recruitment and retention of skilled workers. Hence, this could imply that the skilled workers revived the fortunes of the firms with amenity business growth.

\section{Economic Principles}

Business leaders use available resources for the running of business operations. Ramdani, Primiana, Kaltum, and Azis (2018) found that dynamic capability and supply chain management did not only influence business performance but also have a major impact on collaborative strategies by enhancing effectiveness, but that collaborative intelligence did not significantly influence business performance. Cyron and Zoellick (2018) conducted a study to challenge the dominant assumptions in business growth literature by considering postgrowth economies as an organizational context characterized by natural resource scarcity and a lack of macrolevel economic expansion. Cyron and Zoellick revised six assumptions and redefined business development based on the forces operating in the post-growth economies, which is characterized by the absence of macrolevel economic expansion and scarcity of natural resources. Matalamäki, Vuorinen, Varamäki, and Sorama (2017) conducted a study to determine whether selected large companies grew by adapting to the situation and responding to market demands with their available resources or followed previously determined plans. Matalamäki et al. found that the companies grew by adapting the situation to market demands and previously developed plans.

Furthermore, in a study to examine the institutional determinants on the growth of SMEs using Kosovo as an emerging economy and country in transition based on international business perspective, the researcher 
found that the barriers caused by low levels of professionalism and ethics of officials in institutions, as well as the frequent changes in complicated laws and regulations, have significant impact on increasing transaction costs which is a direct obstacle to the continued growth of SMEs (Peci, 2017). Organizations that want to grow via expansion need to use their resources to some extent.

The existing articles cover growth and expansion of businesses. The scope of operation of the businesses addressed in the articles is for large firms with financial muscles and established structures. Few research articles exist for growth and expansion of nonprofit firms. Hence, this research on strategies to grow and expand a nonprofit business is deemed necessary.

\section{Methodology}

\subsection{Research Method and Design}

I used a qualitative research design to obtain rich data in this study. The research methodology is used to explore the research focus thoroughly (Rutberg \& Bouikidis, 2018). The openness that comes with the use of qualitative methods helps researchers to access rich information from the participants' experiences. Qualitative methods reflect the actions, interactions, and rich understanding of experiences as well as beliefs of participants in a study (Coenen, Stamm, Stucki, \& Cieza, 2012). I used qualitative research to explore the personal views of the participants.

Case study design is used to investigate a real-life phenomenon in-depth (Ridder, 2017). I chose the case study design because the case is of interest to gain a better understanding of issues. Researchers can explore issues and proffer solutions with case study design. Single-case study design enables researchers to have indepth study and gain detailed understanding of a phenomenon, but multiple-case study design helps researchers to gain a broader understanding (Mukhija, 2010). The research design for this study was a singlecase study design to gain an in-depth study and rich understanding of the research topic.

\subsection{Participants}

The participants in my study were senior leaders in the midwestern region who demonstrated the ability to grow and expand a nonprofit business. Qualitative researchers usually deal with a specific set of participants who are knowledgeable about the research topic (Elo et al., 2014; Sarma, 2015). The participants needed to have active employment as leaders in this nonprofit organization, knowledgeable about the operations of the business, and they must have recorded success at growing and expanding the business. The six senior leaders selected met the eligibility criteria for this study. I used purposive sampling technique to select the participants in this study. Researchers use a purposive sampling technique for participant selection and background that is related to the research topic based on their knowledge (Oppong, 2013).

To gain access to the participants, I spoke with one of the senior leaders of my client organization on several occasions to determine some of the organizational leaders who met the participation criteria and were involved in decision making involving the growth and expansion of the nonprofit business. Also, I obtained a signed service order agreement with the representative of the organization. The client's contact also helped me to schedule interview dates with each of the participants.

\subsection{Ethical Consideration}

I initiated the Institutional Review Board (IRB) preapproval process at the inception of this study. My IRB-issued approval number for use in this study is 05-29-19-0979372 and this signifies that my research request met specified requirements of IRB. I used the consent form with the service order provided by Walden University during the consulting capstone. The researcher must conduct the research ethically and abide by the principles of the Belmont Report protocol which are respect for persons, beneficence, and justice (National Commission for the Protection of Human Subjects of Biomedical and Behavioral Research, 1979). I followed the principle of respect for persons by ensuring that the participants were given confidential treatment and that they had the right not to respond to questions that they were not comfortable with as well as the right to withdraw from the interview.

\subsection{Data Saturation}

Data saturation is one of the determinants of the quality of research (Fusch \& Ness, 2015). Yin (2014) noted that data saturation occurs when there is no new data to include in a study. I achieved data saturation when I found that there was no new research data to collect. I assured data saturation in this study after interviewing five participants, reviewing company websites, and company documents.

\subsection{Reliability and Validity}

Reliability and validity are important in studies because researchers use them to assess the quality of a research. Reliability is the ability of a researcher to obtain the same results should the study be repeated (Morse, 2015). I ensured reliability in this study when I allowed participants to respond to the same questions. Also, I verified the accuracy of data collected when I reviewed documentary evidences, information from interviews, and other information from multiple sources. Dependability refers to the stability of data 
(Houghton, Casey, Shaw, \& Murphy, 2013). In this study, I maintained an audit trail to ensure dependability. I offered sufficient data and information on data collection and analysis. I also adopted methodological triangulation to satisfy the dependability criterion of rigor in qualitative research.

Validity refers to the accuracy of the data used for the research (Yilmaz, 2013). Bowen (2008) noted that dependability, transferability, credibility, and confirmability are criteria that must be examined in a qualitative research study to build the extent of trustworthiness of a study. I made detailed descriptions for readers to make informed decisions about whether the results of this study were transferable to other contexts in this research. To ensure credibility and confirmability in this study, I used methodological triangulation of the data I collected from participants' interviews and organizational documents to get a detailed view of the phenomenon and through member checking, ensured a reliable assessment of the findings. I emailed the interview responses and analyses to the participants and received positive responses from the five participants.

\section{Results}

Nonprofit organizations contribute significantly to the development of communities and their benefits to the public. In this study, I explored strategies that business leaders use to grow and expand a nonprofit business. The four themes that emerged were strategic planning, fundraising planning and strategy, resource and financial assessment, and team development and positive working conditions.

I used NVivo 12 to categorize, code, and analyze the data collected to identify themes from the interview transcripts. Yin (2014) noted that researchers use coding to identify themes from interview transcripts to ensure credibility, reliability, and validity. I compared the data analysis results with current literature to determine if the orientation themes as human motivations and economic principles assist leaders of a nonprofit enterprise to grow and expand their business. I transcribed the audio interviews for analysis for member checking.

\section{Discussion and Conclusion}

The results of this study contribute to positive social change by providing leaders of nonprofit organizations with strategies for growth and expansion of their business, which are needed for long-term survival. Growth and expansion strategies ensure long-term survival of nonprofit firms. The leaders of a nonprofit firm in this study noted that nonprofit leaders seeking growth and expansion need to engage in effective strategic planning cycle. An effective strategic planning cycle is comprised of focus or purpose determination, environmental scanning, definition of long-term objectives and short-term goals, definition of an implementation strategy, and evaluation and control of the resultant changes (Paradies, 2010; Roth, 2015). Fundraising planning and strategy are parts of the strategies the participants identified for growth and expansion of a nonprofit business. Sargeant and Shang (2017) noted that fundraising helps a nonprofit organization to achieve its mission and that a fundraising plan is made of three elements which are (1) where are we now? (2) Where do we want to be?, and (3) How are we going to get there?

Any nonprofit firm seeking to achieve its mission of making meaningful impact in the society must have an effective fundraising plan and strategy. Physical resource and financial assessment is another strategy leaders use to grow and expand a nonprofit business. Human resource is one of the physical resources that organizes other categories of resources to provide products. Assessments are needed for quality improvement in any organization (Gökalp \& Demirörs, 2017). Leaders of nonprofit organizations need to be assessing their physical and financial resources continuously to continue to effect quality improvements within their firms.

Nonprofit business leaders use team development and positive working conditions as strategies to grow and expand their business. Team development and team performance are components of team effectiveness. Northouse (2016) highlighted that team effectiveness leads to effective use of resources, improved productivity, increased creativity, increased innovation, increased motivation, better problem solving, better decision making, and better quality products and services. Leaders of nonprofit organizations seeking growth and expansion or survival need to give team development a priority. Suprapto (2017) highlighted that team development leads to communication, collaboration, and effectiveness of work teams. Also, organizational performance improves when team effectiveness is combined with communication and cooperation in the workplace (Suprapto, 2017).

Furthermore, good working conditions influence employee morale. Positive working conditions cause employee job satisfaction, and this leads to employee loyalty (Böckerman \& Ilmakunnas, 2019). Researchers have established a relationship between employee loyalty and organizational performance. Blanaru and Medeleanu (2017) noted that employee loyalty leads to outstanding organizational performance. These strategies align with some of the orientations, economic principles and human motivations, of the theory of growth of the firm.

In the future, I recommend researchers explore how business leaders use an alternative conceptual framework such as RBV to explore how nonprofit leaders use growth and expansion strategies to sustain their business into the foreseeable future. The use of the RBV may give a totally different perspective to the study. Also, researchers may consider the use of a multiple case study design to confirm the strategies that nonprofit 
leaders use to grow and expand their business. The use of a multiple case study design will help researchers to gain a broader understanding of the topic.

\section{References}

Appe, S. (2019). Nonprofit organizations as interpretive communities: Responses to policy reforms and the shaping of civil society in Ecuador. Policy Studies, 4O(6), 609-627. Available at: https://doi.org/10.1080/01442872.2018.1533115.

Blanaru, R. A., \& Medeleanu, C. (2017). Determinant factors of organizational performance in the North-East regional development agency. Scientific Annuals of Alexandru Ioan Cuza University of Iaşi. Sociology \& Social Work, 1O(2), 24-38. Available at: http://anale.fssp.uaic.ro/.

Böckerman, P., \& Ilmakunnas, P. (2019). Do good working conditions make you work longer? Analyzing retirement decisions using linked survey and register data. The Journal of Economics of Ageing. Available at: https://doi.org/10.1016/j.jeoa.2019.02.001.

Bowen, G. A. (2008). Naturalistic inquiry and the saturation concept: A research note. Qualitative Research, 8(1), 137-152. Available at: http://qrj.sagepub.com.ezp.waldenulibrary.org/.

Castaño, M., Méndez, M., \& Galindo, M. (2016). Innovation, internationalization and business-growth expectations among entrepreneurs in the services sector. Journal of Business Research, 69(5), 1690-1695. Available at: https://doi.org/10.1016/j.jbusres.2015.10.039.

Coenen, M., Stamm, T. A., Stucki, G., \& Cieza, A. (2012). Individual interviews and focus groups in patients with rheumatoid arthritis: A comparison of two qualitative methods. Quality of Life Research, 21(2), 359-370. Available at: https://doi.org/10.1007/s11136-011-9943-2.

Cyron, T., \& Zoellick, J. C. (2018). Business development in post-growth economies: Challenging assumptions in the existing business growth literature. Management Revue, 29(3), 206-229. Available at: http://doi.org/10.5771/0935-9915-2018-3-206.

Elo, S., Kaariainen, M., Kanste, O., Polkki, T., Utriainen, K., \& Kyngas, H. (2014). Qualitative content analysis: A focus on trustworthiness. SAGE Open, 4(1), 1-10. Available at: https://doi.org/10.1177\%2F2158244014522633

Fusch, P. I., \& Ness, L. R. (2015). Are we there yet? Data saturation in qualitative research. The Qualitative Report, 2O(9), 1408-1416. Available at: http://nsuworks.nova.edu/tqr/.

Gökalp, E., \& Demirörs, O. (2017). Model based process assessment for public financial and physical resource management processes. Standards in Software Process Improvement and Capability Determination, Computer Standards \& Interfaces, 54(3), 186-193. Available at: https://doi.org/10.1016/j.csi.2016.11.011.

Grillitsch, M., Schubert, T., \& Srholec, M. (2019). Knowledge base combinations and firm growth. Research Policy, 48(1), 234-247. Available at: https://doi.org/10.1016/j.respol.2018.08.009.

Houghton, C., Casey, D., Shaw, D., \& Murphy, K. (2013). Rigour in qualitative case-study research. Nurse Researcher, 20(4), 12-17. Available at: https://doi.org/10.7748/nr2013.03.20.4.12.e326.

Ifekwem, N., \& Adedamola, O. (2016). Survival strategies and sustainability of small and medium enterprises in the Oshodi-Isolo local government area of Lagos State. Acta Universitatis Sapientiae: Economics and Business, 4(1), 103118. Available at: https://doi.org/10.1515/auseb-2016-0006.

Kim, M., Charles, C., \& PettiJohn, S. L. (2019). Challenges in the use of performance data in management: Results of a national survey of human service nonprofit organizations. Public Performance \& Management Review, 42(5), 10851111. Available at: https://doi.org/10.1080/15309576.2018.1523107.

Kor, Y. Y., Mahoney, J. T., Siemsen, E., \& Tan, D. (2016). Penrose's theory of the growth of the firm: An exemplar of engaged scholarship. Production and Operations Management, 25(10), 1727-1744. Available at: https://doi.org/10.1111/poms.12572.

Marshall, C., \& Rossman, G. B. (2016). Designing qualitative research (6th ed.). Thousand Oaks, CA: Sage.

Matalamäki, M., Vuorinen, T., Varamäki, E., \& Sorama, K. (2017). Business growth in established companies; roles of effectuation and causation. Journal of Enterprising Culture, 25(2), 123-148. Available at: https://doi.org/10.1142/S0218495817500054.

Morse, J. M. (2015). Critical analyses of strategies for determining rigor in qualitative inquiry. Qualitative Health Research, 25(9), 1212-1222. Available at: https://doi.org/10.1177\%2F 1049732315588501.

Mukhija, V. (2010). N of one plus some: An alternative strategy for conducting single case research. Journal of Planning Education \& Research, 29(4), 416-426. Available at: https://doi.org/10.1177\%2F0739456X10362770.

National Commission for the Protection of Human Subjects of Biomedical and Behavioral Research. (1979). The Belmont Report: Ethical principles and guidelines for the protection of human subjects of research. Washington, DC. U.S: Department of Health and Human Services.

Northouse, P. G. (2016). Team leadership. Leadership: Theory and practice (7th ed., pp. 362-396). Thousand Oaks, CA: Sage.

Oppong, S. H. (2013). The problem of sampling in qualitative research. Asian Journal of Management Sciences and Education, 2(2), 202-210. Available at: http://www.ajmse.leena-luna.co.jp/.

Paradies, S. (2010). An approach to support strategic planning by ontological structures. Paper presented at the Fourth International Conference.

Peci, F. (2017). Institutional determinants of SME growth: Evidence from Kosovo. International Journal of Economic Perspectives, 4(11), 199-206. Available at: http://www.econ-society.org/.

Penrose, E. T. (2009). In. C. N. Pitelis (Ed.), The theory of the growth of the firm (4th ed.). Oxford: Oxford University Press.

Powe, N. A. (2018). Non-amenity business growth and small town revival. Journal of Rural Studies, 62, 125-133. Available at: https://doi.org/10.1016/j.jrurstud.2018.07.013.

Ramdani, D., Primiana, I., Kaltum, U., \& Azis, Y. (2018). A business growth strategy for digital Telco industry in Indonesia through collaborative strategy by strengthening the dynamic capability and supply chain 
management. The International Journal of Organizational Innovation, 11(2), 50-60. Available at: http://www.ijoionline.org/.

Ridder, H. (2017). The theory contribution of case study research designs. Business Research, 10(2), 281-305. Available at: https://doi.org/10.1007/s40685-017-0045-z.

Roth, W. F. (2015). Strategic planning as an organization design exercise. Performance Improvement, 45(6), 6-12. Available at: https://doi.org/10.1002/pfi.21487.

Rutberg, S., \& Bouikidis, C. D. (2018). Focusing on the fundamentals: A simplistic differentiation between qualitative and quantitative research. Nephrology Nursing Journal, 209-212. Available at: https://www.annanurse.org/resources/products/nephrology-nursing-journal.

Sargeant, A., \& Shang, J. (2017). Fundraising principles and practice (2nd ed.). Hoboken, NJ: Wiley.

Sarma, S. K. (2015). Qualitative research: Examining the misconceptions. South Asian Journal of Management, 22(3), 176191. Available at: http://www.amdisa.org.

Stork, D., \& Woodilla, J. (2008). Nonprofit organizations: An introduction to charity rating sources and cautions in their use. International Journal of Applied Management and Technology, 6(4), 5-28. Available at: http://scholarworks.waldenu.edu/ijamt.

Struwig, F. W., Krüger, J., \& Nuwagaba, G. (2019). The influence of the business environment on the growth of informal businesses in Uganda. The South African Journal of Entrepreneurship and Small Business Management, 11(1), 1-10. Available at: https://doi.org/10.4102/sajesbm.v11i1.200.

Suprapto, W. (2017). The influence of individual knowledge and work team development to the manufacturing company performance of East Java. Journal of Management and Entrepreneurship, 19(1), 22-27. Available at: https://doi.org/10.9744/jmk.19.1.22-27.

U. S. Small Business Administration (SBA). (2018). Frequently asked questions about small business. Retrieved from: https://www.sba.gov/sites/default/files/advocacy/Frequently-Asked-Questions-Small-Business-2018.pdf.

Yilmaz, K. (2013). Comparison of quantitative and qualitative research traditions: Epistemological, theoretical, and methodological differences. European Journal of Education, 48(2), 311-325. Available at: https://doi.org/10.1111/ejed.12014.

Yin, R. K. (2014). Case study research: Design and methods (5th ed.). Thousand Oaks, CA: Sage. 